\title{
A new continuous flow-through structured reactor for the photodegradation of aqueous contaminants
}

\author{
Amparo Fernández-Pérez, Verónica Rodríguez-Casado, Teresa Valdés-Solís and \\ Gregorio Marbán* \\ Instituto Nacional del Carbón (INCAR-CSIC) - c/Francisco Pintado Fe 26, \\ 33011-Oviedo (Spain). Tel. +34 985119090; Fax +34985297662
}

\begin{abstract}
A flow-through photo reactor with a stainless steel mesh-supported $\mathrm{ZnO}$ catalytic disc has been designed in this work. The preparation method of the catalyst includes the use of Triton ${ }^{\mathrm{TM}} \mathrm{X}-100$ and methylene blue (MB) in order to enhance the homogeneity of the $\mathrm{ZnO}$ and its adhesion to the mesh. The catalysts exhibit a high surface area $\left(\sim 100 \mathrm{~m}^{2} / \mathrm{g}\right)$. The photocatalytic reaction is restricted to the most external non-polar edges of the $\mathrm{ZnO}$ nanosheets due to the low $\mathrm{pH}$ of the $\mathrm{MB}$ solution and to the fact that the polar surfaces are hydrophobic. Despite this, the performance of the flow-through reactor is superior to that of other micro fluidic systems. The catalyst undergoes a slight deactivation during the reaction, though the activity can be restored, without causing any structural changes, by passing water through the catalyst under UV irradiation. The loss of $\mathrm{ZnO}$ through photocorrosion is low, especially when compared to the loss experienced by the same catalyst prepared without using methylene blue.
\end{abstract}

\footnotetext{
• Corresponding author: greca@incar.csic.es
} 
Keywords: Photocatalysis; flow-through reactor; $\mathrm{ZnO}$; catalyst regeneration; methylene blue 


\section{Introduction}

With waterborne diseases causing around two million deaths each year, water treatment is one of the challenges facing mankind in the $21^{\text {st }}$ century. Water treatment technologies include Advanced Oxidation Processes (AOP) to accelerate the oxidation and destruction of a wide range of organic contaminants. Photocatalytic methods that employ AOP under $\mathrm{UV}$ or sunlight irradiation to obtain clean water leave only $\mathrm{CO}_{2}$ and inorganic ions as residuals $[1,2]$. However, most photocatalytic reactors employed to date operate under severe mass transfer limitations (immobilized bulk reactors) and/or with a low photon transfer efficiency (slurry bulk reactors) [3]. Micro-reactors or micro-fluidic reactors [49], based on micro-channels, micro-capillaries or planar micro-chambers, allow an optimal distribution of light and present large values of surface area per unit volume $\left(1 \times 10^{4}-3 \times 10^{5} \mathrm{~m}^{2} / \mathrm{m}^{3}\right)$, facilitating the transfer of the contaminant to the catalyst surface. However, micro-fluidic reactor chips operate under low flow rates (around $1 \mathrm{~cm}^{3} / \mathrm{h}$ ) and scaling-up is a challenging task, even though lithographic techniques for fabricating micro-reactors are now readily available. Other typical drawbacks of micro-reactors, such as fouling and clogging, frequent repacking or reactivation (regeneration), leaks between channels, malfunctioning of distributors, etc., are also multiplied when scaling up the reaction system. As an alternative to standard micro-fluidic reactors, we present in this work a novel photocatalytic flow-through reactor based on a stainless steel wire micromesh (SSWM)-supported photocatalyst. This special type of supported catalyst has been developed in recent years and tested in batch reactors at lab scale for the photodegradation of organic contaminants in water [10-18]. Our research group has successfully fabricated SSWM-supported $\mathrm{ZnO}$ and $\mathrm{TiO}_{2}$ porous nanosheets, with high yields of active phase on the wire mesh surface, very high values of specific surface area and a good photostability by using post-synthesis additives [14-18]. However, in recent 
ultrasonic tests an insufficient adhesion of the photocatalytic particles to the SSWM was observed, together with an occasional lack of uniformity in the distribution of the particles on the mesh [17-20]. In this work we have modified the fabrication method in order to improve the adhesion, homogeneity and photostability of the catalyst, without the need for post-synthesis additives, and established a protocol to maintain the high values of the specific surface area values of the porous $\mathrm{ZnO}$ nanosheets.

The flow-through reactor devised in this work combines the concepts of piston flow and micro-reactor by using a SSWM-based photocatalyst with a very high irradiated surface area per unit volume $\left(9 \times 10^{5} \mathrm{~m}^{2} / \mathrm{m}^{3}\right)$ and a high photon transfer efficiency. In addition, this reactor is easily up-scalable and permits the in situ regeneration of the photocatalyst. The reactor has been tested for the photodegradation of methylene blue (MB) in water with catalysts synthesized under different conditions. Methylene blue is a dye that is extensively used in industrial applications and in photocatalytic studies [21, 22]. Finally, the photocatalytic results are compared with those reported in the literature for microfluidic systems.

\section{Experimental}

\section{Catalyst synthesis}

The standard method of synthesis of the SSWM-supported $\mathrm{ZnO}$ samples is described elsewhere [23] and summarized in the Supplementary Information (SI). This method was subjected to repeatability problems as a result of insufficient wetting of the mesh in the synthesis solution, due to the contact between the mesh and the autoclave or to bubbles clinging to the mesh surface during heating in the oven. This problem was solved by 
adding a surfactant $\left(\right.$ Triton $^{\mathrm{TM}} \mathrm{X} 100$, Chem Lab) to the synthesis solution ( $85-100$ $\left.\mathrm{mg} / 100 \mathrm{~cm}^{3}\right)$.

The adhesion of the $\mathrm{ZnO}$ nanoparticles to the SSWM was improved by adding Triton and monohydrated methylene blue (Sigma Aldrich, $3 \mathrm{~cm}^{3}$ of a $5 \mathrm{ppm}$ aqueous solution added to the synthesis mixture).

\section{Catalyst characterization}

The morphological and textural properties of the samples were studied by means of scanning electron microscopy (SEM, FEI Quanta FEG 650 model). The X-ray diffraction (XRD) patterns were recorded on a Bruker D8 Advance instrument operating at $20 \mathrm{kV}$ and $5 \mathrm{~mA}$ using $\mathrm{Cu} \mathrm{K} \alpha$ radiation $(\lambda=0.15406 \mathrm{~nm})$. The crystal size values were estimated from the (100) peak of the XRD pattern by means of Scherrer's equation. The BET specific surface area was calculated via the single-point method by means of $\mathrm{N}_{2}$ physisorption at $-196^{\circ} \mathrm{C}$ in a Micromeritics Autochem II chemisorption analyser. $\mathrm{N}_{2}$ adsorption-desorption isotherms of selected samples were performed at $-196^{\circ} \mathrm{C}$ in a Micromeritics ASAP 2020 analyser. The pore size distribution (PSD) was calculated from the $\mathrm{N}_{2}$ adsorption isotherms by means of the Kruk-Jaroniec-Sayari method [24]. UV-VIS diffuse reflectance spectroscopy measurements were carried out to determine the band-gap energy value in a Shimadzu UV-2460 spectrophotometer equipped with an integrating sphere. Adhesion of the $\mathrm{ZnO}$ nanosheets to the SSWM was tested by introducing the catalyst into a polypropylene flask filled with water and immersing the flask in an ultrasonic bath for $10 \mathrm{~min}$. To determine the point of zero charge $\left(\mathrm{pH}_{\mathrm{pzc}}\right)$ of the catalysts and of the commercial $\mathrm{ZnO}$ powder employed (ChemLab, CL.002626.0250), the $\mathrm{pH}$ drift method was used [25]. In brief, $50-\mathrm{cm}^{3}$ aqueous solutions of $\mathrm{NaCl}(0.01 \mathrm{M})$ 
were prepared with $\mathrm{pH}$ values in the 4-10 range by adding either $\mathrm{HCl}(0.1 \mathrm{M})$ or $\mathrm{NaOH}$ (0.1 M). Samples of/with around $50 \mathrm{mg}$ of zinc oxide were added to each solution at room temperature and vigorously shaken for 2 days. The initial and final $\mathrm{pH}$ values were measured using a GLP21 pHmeter (Crison). The intersection of the curves formed by both sets of values plotted against the initial $\mathrm{pH}$ served to determine the $\mathrm{pH}_{\mathrm{pzc}}$ of the analysed sample. The amount of methylene blue adsorbed by the SSWM-supported catalysts at different $\mathrm{pH}$ values was evaluated by introducing catalyst samples in $50-\mathrm{cm}^{3}$ aqueous solutions of $\mathrm{MB}(10 \mathrm{ppm})$ at specific $\mathrm{pH}$ values, adjusted by adding small amounts of $\mathrm{HCl}(0.1 \mathrm{M})$ or $\mathrm{NaOH}(0.1 \mathrm{M})$. The solutions were mechanically shaken for one day to ensure equilibrium adsorption. The concentration of MB before and after equilibrium adsorption was analysed using an UV-Vis spectrometer (Shimazdu UV2401PC) from the absorbance at $665 \mathrm{~nm}$.

\section{Continuous operation flow-through photocatalytic reactor}

The reactor was a standard polystyrene filter holder in which the filter was replaced by a disc-shaped catalyst (37 mm diameter, $\sim 112 \mu \mathrm{m}$ thickness). Figures 1A-B show a photograph and a schematic representation of the reaction system. A four-channel peristaltic pump (Ismatec Ecoline VC-MS/C44-12 with Pharmed BPT tubing, $0.25 \mathrm{~mm}$ i.d.) is used to move a liquid stream through the reactor in two possible modes: in the reaction mode the peristaltic pump propels a MB solution towards the catalyst disc from the lower part of the holder, whereas in the regeneration mode the direction of the liquid is reversed and water is pumped towards the catalyst disc from the upper part of the holder. Two three-way valves allow the liquids to be changed from one mode to another

(Figure 1). In both modes the liquid homogeneously traverses the catalyst disc through small openings $(\sim 30 \mu \mathrm{m})$ in the catalytic mesh (Figure $2 \mathrm{~B})$, in a way similar to micro- 
fluidic devices. The liquid flows in a plug-flow fashion, and enters the voids of the mesh homogeneously, the small size of the voids ensuring that external mass transfer resistance is kept to a minimum The level of solution covering the disc is kept to a minimum $(\sim 1 \mathrm{~mm})$ by using a Viton ${ }^{\circledR} \mathrm{O}$-ring between the disc and a transparent quartz disc (1 mm thickness) as a top cap (Figure 1B). Two small perforations in the polystyrene holder, at the level of the upper part of the separation O-ring, connected to small pipes ( 1 mm i.d.) allow the liquid to exit. To enable the liquid to pass from the inner side of the O-ring to the outlet pipes, a small piece of SSWM $\left(\sim 3 \mathrm{~mm}^{2}\right)$ is located next to each perforation, between the O-ring and the quartz disc. A perforation in the polystyrene holder, below the catalytic disc, connected to a relief pipe (shown in Figure 1A) is used to eliminate any liquid excess in case of overpressure. A second O-ring placed over the quartz disc guarantees the absence of leaks. A piece of the polystyrene filter ensures the O-ring is tightly pressed against the quartz disc (Figure 1B). An $8 \mathrm{~mm}$ UV light source guide (Opsytec Dr Gröbel LQ-400 model, 400W, 365nm, 88\% UV-A) is used to illuminate the upper surface of the catalyst disc $(33.5 \mathrm{~mm}$ irradiated diameter) from a controllable distance. The irradiated surface area (upper side geometric area) per unit volume of the micro-reactor is $9 \times 10^{5} \mathrm{~m}^{2} / \mathrm{m}^{3}$. In principle, this reactor should be easy to scale up to allow large flow rates, as illustrated in Figure S1 (Supplementary Information).

\section{Photocatalytic and regeneration tests in the flow-through reactor}

Continuous operation photodegradation experiments were performed using a methylene blue (MB) aqueous solution $\left(\mathrm{C}_{0}=10 \mathrm{ppm}\right)$. The $\mathrm{MB}$ solution was magnetically stirred and air bubbled in a $2 \mathrm{~L}$ amber glass bottle. With the aid of the peristaltic pump (reaction mode) a constant flow of MB solution was directed into the reactor from its lower part. The liquid stream exiting the reactor was collected in test tubes at controlled time intervals 
by a Frac-920 fraction collector (GE Healthcare Life Sciences). The collected samples were analysed in an UV-Vis spectrometer (Shimazdu UV-2401PC), a TOC analyser (Shimazdu TOC-V CPH + ASI-V) and an ICP-MS analyser (Agilent 7700x model) in order to evaluate the MB concentration (absorbance at $665 \mathrm{~nm}$ ), the total organic content, and the $\mathrm{Zn}^{2+}$ concentration, respectively.

In a typical reaction experiment, a stream of $\mathrm{MB}$ solution at a rate of $20 \mathrm{~cm}^{3} / \mathrm{h}$ was passed through the reactor under darkness to ensure equilibrium adsorption of $\mathrm{MB}$ onto the catalytic disc. Then, the UV light source, with its tip positioned $26.6 \mathrm{~mm}$ above the catalytic mesh, was turned on to initiate the photocatalytic reaction. At this height, average irradiance in the $230-400 \mathrm{~nm}$ wavelength range of the catalyst disc was 10 $\mathrm{mW} / \mathrm{cm}^{2}$ (RM-12 radiometer UVBB-sensor provided by Opsytec Dr Gröbel).

In specific cases, after the reaction the reactor was operated in regeneration mode. In this mode water was pumped for about 5 hours to the reactor from the upper side of the catalytic disc by changing the position of the three way valves and reversing the flow of the peristaltic pump, while the UV light source continued to illuminate the catalyst disc.

\section{Results and discussion}

Stainless steel-wire mesh supported ZnO. characterisation

As mentioned in the experimental section the standard synthesis method needs to be improved to ensure homogeneity of the samples and adhesion to the support. The lack of homogeneity between samples can be counteracted by adding of a small amount of surfactant (Triton ${ }^{\mathrm{TM}} \mathrm{X}-100$ ), as shown in Figure 2A, where the high homogeneity of the $\mathrm{ZnO}$ film is clearly observed. Furthermore, the microwires of the mesh were more tightly covered by the $\mathrm{ZnO}$ nanosheets, as can be observed in Figures 2B-C. 
The adhesion of the $\mathrm{ZnO}$ particles to the mesh was partially improved by adding Triton ${ }^{\mathrm{TM}}$ $\mathrm{X}-100$, as can be seen in Figure 3 ( $\mathrm{ZnO}$ losses in the ultrasonic adhesion test decreased from $19.6 \pm 16.0 \mathrm{wt} . \%$ to $15.9 \pm 14.7 \mathrm{wt} . \%$ ), probably due to better penetration of the mesh voids by the synthesis solution. A more significant improvement to the adhesion of the $\mathrm{ZnO}$ particles was observed when methylene blue was added to the synthesis solution. The $\mathrm{ZnO}$ losses were drastically reduced in the ultrasonic test to below $5 \mathrm{wt} \%$ (Figure 3). The mechanism that governs the methylene blue action in this process is currently under examination.

Modification of the synthesis method does not cause any significant changes in the morphological, structural or textural properties of the catalyst, reported in the works by $\mathrm{Vu}$ et al. $[16,23]$. In the case of the sample calcined at $210^{\circ} \mathrm{C}(\sim 20 \mathrm{wt} . \% \mathrm{ZnO})$ the $\mathrm{XRD}$ patterns (Figure 2D) correspond in both cases (modified and unmodified methods) to the typical hexagonal wurtzite-type ZnO (JCPDS No. 36-1451), with a crystal size of 8.8-9.4 $\mathrm{nm}$, as evaluated by Scherrer's equation. The $\mathrm{N}_{2}$ physisorption isotherms (Figure 2E) are almost coincident and typical of mesoporous materials (type IV isotherm), with a specific surface area of $105-115 \mathrm{~m}^{2} / \mathrm{g}$, a bimodal pore size distribution (inset of Figure 2E) and a similar pore volume of around $0.3 \mathrm{~cm}^{3} / \mathrm{g}$. In the case of samples with different $\mathrm{ZnO}$ yields but the same calcination temperature $\left(210^{\circ} \mathrm{C}\right)$, there are random variations in crystal size $(7.5-9.4 \mathrm{~nm})$ and specific surface area $\left(102-124 \mathrm{~m}^{2} / \mathrm{g}\right)$. Table 1 also shows that an increase in the calcination temperature produces the corresponding increase in the $\mathrm{ZnO}$ crystal size (up to $22.3 \mathrm{~nm}$ at $450^{\circ} \mathrm{C}$ ) accompanied by a concomitant decrease in specific surface area (down to $24.3 \mathrm{~m}^{2} / \mathrm{g}$ at $450^{\circ} \mathrm{C}$ ). The average band-gap energy value obtained from Tauc plots (Supplementary Information Figure S3) of the Kubelka-Munk function for samples with different $\mathrm{ZnO}$ yields calcined at $210^{\circ} \mathrm{C}$ (Table 1) was $3.31 \pm 0.05 \mathrm{eV}$, as expected for pure $\mathrm{ZnO}$ [26]. The band-gap values of the samples calcined at higher temperatures 
show a slight decrease (Table 1) contrary to the findings of some authors [27, 28] but in agreement with the results of other authors [29], who attribute the decrease in band-gap with calcination temperature to the increase in particle size, since they believe that "as the particle size increases, the number of atoms that form a particle also increases which consequently renders the valence and conduction electrons more attractive to the ion core of the particles, hence decreasing the band gap of the particles" [29].

\section{Effect of catalyst properties on the MB photodegradation in the flow-through reactor}

Figure 4 shows the results of photodegradation in the flow-through reactor of a $20 \mathrm{~cm}^{3} / \mathrm{h}$ MB solution $\left(\mathrm{C}_{0}=10 \mathrm{ppm}\right)$ during $\sim 17 \mathrm{~h}$ using catalysts with different amounts of $\mathrm{ZnO}$ (yield) calcined at $210^{\circ} \mathrm{C}$. The $\mathrm{MB}$ conversion values $\left(\mathrm{X}_{\mathrm{MB}}\right)$ at 3 and $17 \mathrm{~h}$ are presented in Table 2. A small part of these conversion values corresponds to photolysis $(\sim 4.5 \%$, evaluated in the absence of catalyst) as it is indicated in Figure 4. From the results plotted in this figure and listed in Table 2 it can be concluded that the $\mathrm{ZnO}$ mass $\left(\mathrm{W}_{\mathrm{ZnO}}\right.$ in Table 2) has no apparent effect on the MB conversion values, which are randomly distributed among the $\mathrm{ZnO}$ mass values. The average conversion at $3 \mathrm{~h}$ is $64.6 \pm 3.7 \%$, decreasing slightly and almost linearly to $57.9 \pm 4.2 \%$ at $17 \mathrm{~h}$. Two reasons may explain the absence of a relation between the $\mathrm{ZnO}$ mass and the $\mathrm{MB}$ conversion; i) hardly any $\mathrm{MB}$ is adsorbed onto the surface of the catalyst and/or ii) the UV light only illuminates the outermost surface of the catalyst. The adsorption of an ionic dye depends on the point of zero charge $\left(\mathrm{pH}_{\mathrm{pzc}}\right)$ of the adsorbent. Thus, the adsorption of $\mathrm{MB}$ (a cationic dye) will be favoured at $\mathrm{pH}$ values above the $\mathrm{pH}_{\mathrm{pzc}}$, in which case the surface of the adsorbent will be negatively charged. Conversely, in the case of $\mathrm{pH}<\mathrm{pH}_{\mathrm{pzc}}$, the surface of the adsorbent will be positively charged, and this will hinder the adsorption of the cationic dye. Figure 5 shows the results of applying the $\mathrm{pH}$ drift method [25] to evaluate the $\mathrm{pH}_{\mathrm{pzc}}$ values of a 
SSWM-supported catalyst $\left(\mathrm{T}_{\mathrm{C}}=210^{\circ} \mathrm{C}, \mathrm{ZnO}\right.$ yield $\left.=\sim 20 \mathrm{wt} . \%\right)$ and a commercial $\mathrm{ZnO}$ powder (ChemLab, CL.002626.0250). The points of intersection in Figure 5 indicate the $\mathrm{pH}_{\mathrm{pzc}}$ values: 7.5 for the SSWM-supported catalyst and 8 for the commercial powder. The $\mathrm{pH}$ of the $10 \mathrm{ppm} \mathrm{MB}$ solution used in the photodegradation experiments is 6.1 , similar to that of the deionized water. Specific adsorption experiments confirmed the insignificant $\mathrm{MB}$ adsorption at the $\mathrm{pH}$ of the $\mathrm{MB}$ solution $(0.6 \mathrm{mg} / \mathrm{g}$ at $\mathrm{pH}=6.5)$. Only when the $\mathrm{pH}$ of the solution was increased to values above the $\mathrm{pH}_{\mathrm{pzc}}$ of the SSWMsupported catalyst, was the adsorption of $\mathrm{MB}$ apparent $(2.4 \mathrm{mg} / \mathrm{g}$ at $\mathrm{pH}=9.5)$. It is interesting to note that the $\mathrm{pH}_{\mathrm{pzc}}$ of the SSWM-supported catalyst is somewhat lower than the values reported in the literature for $\mathrm{ZnO}$ nanoparticles, between 8.5 and $9.5[25,30$ 32]. SSWM-supported $\mathrm{ZnO}$ nanosheets are polar, but the non-polar edges of the nanosheets are preferentially exposed due to the alignment of the nanosheets (see Figure $2 \mathrm{C}$ and discussion in [19]). Assuming that water is not adsorbed on the polar planes (this hypothesis is supported by our previous work [20] and widely justified in the supplementary information), then MB would only react on the most external non polar edges of the sheets. Therefore, almost no $\mathrm{MB}$ (at $\mathrm{pH}<\mathrm{pHpzc}$ ) is adsorbed on the surface of the catalyst, even on the external surface of the nanosheets, but only on their most external edges. This would explain why the MB conversion is only randomly affected by the $\mathrm{ZnO}$ yield. In spite of the low utilisation of the catalyst surface, its photoactivity in the flow-through reactor is exceedingly high, as is borne out by a comparison with other micro-reaction systems, which opens the door to a future investigation of the photodegradation of anionic dyes, for which a significant adsorption might be expected.

Figure 6 shows the evolution of MB conversion with time for the $\sim 20 \mathrm{wt} . \% \mathrm{ZnO}$ catalysts calcined at different temperatures $\left(210-450^{\circ} \mathrm{C}\right)$. The conversion values at short reaction times decrease when $\mathrm{T}_{\mathrm{C}}$ increases from 210 to $250^{\circ} \mathrm{C}$, and then show a significant increase 
for higher calcination temperatures (Table 2). The inset in Figure 6 shows the slope of the line that fits the curves from the point of maximum conversion until the end of the reaction (minimum conversion), a value equivalent to the rate of deactivation during the reaction $\left(-\mathrm{dX} \mathrm{MB}_{\mathrm{MB}} / \mathrm{dt}\right)$. It can be seen that the deactivation rate clearly increases with the calcination temperature. A more crystalline $\mathrm{ZnO}$ seems to enhance the deactivation. Deactivation takes place via the accumulation of volatile compounds on the surface of the material that turn the catalyst blackish (left photograph in Figure 7). These compounds are volatilized under an inert atmosphere at temperatures below $600^{\circ} \mathrm{C}$ without leaving carbonaceous residues.

$\mathrm{MB}$ mineralization and $\mathrm{ZnO}$ losses during the reaction in the flow-through reactor

The values of total organic carbon conversion $\left(\mathrm{X}_{\mathrm{TOC}}, \%\right)$ obtained by TOC analysis with samples acquired at reaction times of around $17 \mathrm{~h}$ are presented in Table 2 . The average ratio of TOC conversion to MB conversion (at $17 \mathrm{~h}$ ) is $0.45 \pm 0.08$ for all the experiments listed in Table 2. This value is similar to that obtained for batch photocatalytic systems based on $\mathrm{TiO}_{2}[33]$ and better than that reported for other reaction systems such as the dielectric barrier discharge non-thermal plasma reactor [34].

Table 2 also shows the losses of $\mathrm{ZnO}$ during the reaction $\left(\mathrm{L}_{\mathrm{ZnO}}\right.$, wt.\%) as a consequence of photocorrosion [35-37], as determined from the evolution of the $\mathrm{Zn}^{2+}$ concentration in the exit stream (analysed by ICP-MS). In a previous work [16], a SSWM-supported ZnO catalyst $\left(\mathrm{T}_{\mathrm{C}}=210^{\circ} \mathrm{C}, \mathrm{ZnO}\right.$ yield $\left.=\sim 20 \mathrm{wt} . \%\right)$ prepared without the use of Triton ${ }^{\mathrm{TM}} \mathrm{X}-100$ and/or $\mathrm{MB}$ in the synthesis solution was subjected to batch experiments of $\mathrm{MB}$ photodegradation under UV irradiation. After one hour of reaction the sample had lost almost 60 wt. $\%$ of its initial $\mathrm{ZnO}$ content [16]. Table 2 shows that the maximum loss of 
$\mathrm{ZnO}$ with the catalyst synthesized using the modified procedure, as described in the present work, is $\sim 13.7$ wt.\% for the catalyst with the lowest $\mathrm{ZnO}$ yield, decreasing with the increase in $\mathrm{ZnO}$ yield down to its lowest value of $\sim 1.0 \mathrm{wt} . \%$. This inverse relationship between the $\mathrm{ZnO}$ yield and the fractional $\mathrm{ZnO}$ losses during the reaction results in a similar absolute $\mathrm{ZnO}$ loss for all catalysts which, at the end of reaction $(\sim 17 \mathrm{~h})$, leaves an average $\mathrm{Zn}^{2+}$ concentration in all the treated water samples of $3.1 \pm 1.0 \mathrm{ppm}$, an average which includes the values obtained with the catalysts calcined at different temperatures. The $\mathrm{Zn}^{2+}$ concentration diminishes over longer reaction times, since the photocorrosion reaction rate follows a descending trend similar to that of the MB photodegradation rate. Although one of the purposes of future works will be to eliminate any loss of catalyst, it is worth noting that drinking water with $3 \mathrm{ppm}$ of zinc is far from being a risk to the human health according to the World Health Organization [38]. As can be seen in Table 2, the $\mathrm{ZnO}$ losses from photocorrosion decrease with the calcination temperature (from $3.6 \mathrm{wt} . \%$ at $210^{\circ} \mathrm{C}$ to $1.2 \mathrm{wt} . \%$ at $450^{\circ} \mathrm{C}$ ). This may be due to the progressive annealing of reactive photocorrosion centres as the calcination temperature increases.

The fact that the absolute amount of $\mathrm{Zn}^{2+}$ released into the water is independent of the $\mathrm{ZnO}$ mass in the catalyst is further proof of the hydrophobic behaviour of the polar faces of the $\mathrm{ZnO}$ nanosheets. As with $\mathrm{MB}$ photodegradation, photocorrosion only takes place on the surface of the most external edges of the nanosheets, where water can exert its photocorrosive activity according to the reactions [35-37]:

$\mathrm{ZnO}+2 \mathrm{~h}^{+}+\mathrm{nH}_{2} \mathrm{O} \rightarrow \mathrm{Zn}(\mathrm{OH})_{\mathrm{n}}^{(2-\mathrm{n})+}+1 / 2 \mathrm{O}_{2}+\mathrm{nH}^{+}$

$\mathrm{ZnO}+2 \mathrm{~h}^{+} \rightarrow \mathrm{Zn}^{2+}+1 / 22 \mathrm{O}_{2}$

where $\mathrm{h}^{+}$are the positive holes created by the action of UV irradiation. It seems that all significant reactions [photodegradation, deactivation and photocorrosion] take place at 
the external non-polar edges of the nanosheets, to which water and methylene blue have access.

Regeneration of the SSWM-supported ZnO catalyst

Due to the slight deactivation experienced by the catalysts during the reaction (Figures 4 and 6), a SSWM-supported catalyst with a $\sim 20 \mathrm{wt} . \% \mathrm{ZnO}$ yield and calcined at $250^{\circ} \mathrm{C}$ was used to explore the regeneration of the catalyst between successive cycles of reaction in the flow-through reactor. The regeneration stage consisted in setting the reactor to regeneration mode and passing water through the catalyst under UV irradiation for about 5 hours. The methylene blue conversion curves for each cycle are plotted in Figure 7. The photographs included in the figure show the catalyst disc at the end of the first reaction cycle (left) and after the first regeneration stage (right). As can be clearly observed, the black spots formed during the reaction on the surface of the material have been eliminated by the combined action of water and light during the regeneration stage. The second reaction stage shows a clear reactivation of the catalyst, which is less pronounced in the third reaction stage. Successive cycles show a stable reactivation. The losses of $\mathrm{ZnO}$ during the successive reaction cycles (Figure 7) remain more or less stable in the 1.4-1.9 wt.\% range. The specific surface area of the catalyst was measured before reaction, at the end of the first reaction cycle and after the first regeneration stage, yielding values of $74.5,75.9$ and $76.4 \mathrm{~m}^{2} / \mathrm{g}$, respectively. No structural changes were detected in these samples by XRD analysis. This is conclusive proof that the reaction is restricted to the surface of the most external edges of the nanosheets, where the volatile compounds are neither a source of additional surface area nor a material blocking the porosity of the catalyst. 
Comparison of the flow-through reactor with micro-fluidic reactors

Finally, if the catalytic disc is considered as a micro-reactor itself, it might be worthwhile to make a comparison between the performance of the flow-through reactor and other micro-fluidic systems used for the photodegradation of methylene blue [39-41]. Table 3 shows the main characteristics of systems we have compared, including the type of catalyst, UV lamp, irradiance, reactor volume and reaction parameters. On the basis of the maximum conversion values reported by the different authors the activity expressed as the amount of MB photodegraded per micro-reactor volume and time can be evaluated. It can be seen that, even with a value of irradiance generally lower than that used in the other reactor systems and a more modest catalyst $\left(\mathrm{ZnO}\right.$ vs $\mathrm{TiO}_{2}$ or $\left.\mathrm{BiVO}_{4}\right)$ the flowthrough reactor yields a superior activity.

It is important to note that the reactor described in the present work shows a low pressure drop and no obstruction problems. To employ solar radiation, the catalyst formulation can be easily changed by doping of $\mathrm{ZnO}$ or by synthesizing other oxides $\left(\mathrm{TiO}_{2}, \mathrm{Fe}_{2} \mathrm{O}_{3}\right.$, etc.) from the SSWM-supported $\mathrm{ZnO}$ by means of sacrificial template accelerated hydrolysis $[15,23,42]$. Low cost, high availability, easy handling, flexibility, mechanical stability and scalability are other advantages that favour this kind of reactor.

\section{Conclusions}

A flow-through reactor has been designed for the continuous degradation of contaminants in water. It employs a catalytic disc, stainless steel wire micromesh-supported $\mathrm{ZnO}$ nanosheets, whose preparation method has been improved with respect to previous works by adding Triton ${ }^{\mathrm{TM}} \mathrm{X}-100$ and methylene blue to the synthesis solution. This modification 
yields a catalyst with a homogeneous distribution and an enhanced adhesion of the $\mathrm{ZnO}$ particles on/to the mesh and a high specific surface area $\left(>100 \mathrm{~m}^{2} / \mathrm{g}\right)$. However, in the photodegradation of MB performed under UV irradiation it has been proved that most of the surface of the catalyst particles is not in contact with the MB solution, and that the reaction is restricted to the most external non-polar edges of the $\mathrm{ZnO}$ nanosheets. This is a consequence of the hydrophobicity of the polar faces of the nanosheets and the low $\mathrm{pH}$ of the $\mathrm{MB}$ solution, i.e. below the $\mathrm{ZnO}$ point of zero charge. Nevertheless, the performance of this reactor is exceedingly high and superior to that of other micro-fluidic systems described in the literature. The catalyst undergoes a slight deactivation during reaction due to the accumulation of black volatile compounds on its surface. Its activity can be restored by passing water through the catalyst under UV irradiation. The loss of $\mathrm{ZnO}$ through photocorrosion is very low, especially when compared to the loss experienced by the catalyst when prepared without the addition of methylene blue to the synthesis solution. The reactor described in the present work shows a low pressure drop and no obstruction problems.

\section{Acknowledgements}

The financial support for this research work provided by the Spanish MINECO (CTM2014-56770-R) and FEDER Funds (GRUPIN14-102, Principado de Asturias) is gratefully acknowledged.

\section{Reference list}

[1] M.N. Chong, B. Jin, C.W.K. Chow, C. Saint, Recent developments in photocatalytic water treatment technology: A review, Water Research, 44 (2010) 2997-3027. 
[2] S. Parsons, Advanced oxidation processes for water and wastewater treatment, Water Intelligence Online, 4 (2005) 9781780403076.

[3] N. Wang, X. Zhang, Y. Wang, W. Yu, H.L. Chan, Microfluidic reactors for photocatalytic water purification, Lab on a Chip, 14 (2014) 1074-1082.

[4] X. Li, H. Wang, K. Inoue, M. Uehara, H. Nakamura, M. Miyazaki, E. Abe, H. Maeda, Modified micro-space using self-organized nanoparticles for reduction of methylene blue, Chemical Communications, (2003) 964-965.

[5] Z. Zhang, H. Wu, Y. Yuan, Y. Fang, L. Jin, Development of a novel capillary array photocatalytic reactor and application for degradation of azo dye, Chemical Engineering Journal, 184 (2012) 9-15.

[6] Y. Matsushita, N. Ohba, S. Kumada, K. Sakeda, T. Suzuki, T. Ichimura, Photocatalytic reactions in microreactors, Chemical Engineering Journal, 135, Supplement 1 (2008) S303-S308.

[7] H. Lindstrom, R. Wootton, A. Iles, High surface area titania photocatalytic microfluidic reactors, AIChE Journal, 53 (2007) 695-702.

[8] L. Lei, N. Wang, X.M. Zhang, Q. Tai, D.P. Tsai, H.L.W. Chan, Optofluidic planar reactors for photocatalytic water treatment using solar energy, Biomicrofluidics, 4 (2010) 043004.

[9] S. Das, V.C. Srivastava, Recent Advances in Fabrication of Photocatalytic MicroReactor, in: Materials Science Forum, Trans Tech Publ, 2016, pp. 156-167.

[10] M.-H. Hsu, C.-J. Chang, Ag-doped $\mathrm{ZnO}$ nanorods coated metal wire meshes as hierarchical photocatalysts with high visible-light driven photoactivity and photostability, Journal of Hazardous Materials, 278 (2014) 444-453.

[11] S. Jung, K. Yong, Fabrication of $\mathrm{CuO}-\mathrm{ZnO}$ nanowires on a stainless steel mesh for highly efficient photocatalytic applications, Chemical Communications, 47 (2011) 2643-2645.

[12] M. Bestetti, D. Sacco, M.F. Brunella, S. Franz, R. Amadelli, L. Samiolo, Photocatalytic degradation activity of titanium dioxide sol-gel coatings on stainless steel wire meshes, Materials Chemistry and Physics, 124 (2010) 1225-1231.

[13] S. Yanagida, A. Nakajima, Y. Kameshima, K. Okada, Photocatalytic Destruction of 1,4-Dioxane in Aqueous System by Surface-Roughened $\mathrm{TiO}_{2}$ Coating on Stainless Mesh, Key engineering materials, 412 (2009) 137-141.

[14] T.T. Vu, A.B. Rodil, G. Marbán, T. Valdés-Solís, Nanostructured stainless steel wire mesh-supported $\mathrm{Cd}_{\mathrm{x}} \mathrm{Zn}_{1-\mathrm{x}} \mathrm{O}$ : A stable photocatalyst under visible and ultraviolet irradiation, Journal of Environmental Chemical Engineering, 2 (2014) 1612-1620.

[15] T.T. Vu, T. Valdés-Solís, G. Marbán, High surface area stainless steel wire meshsupported $\mathrm{TiO} 2$ prepared by sacrificial template accelerated hydrolysis. A monolithic photocatalyst superior to P25 TiO2, Journal of Environmental Chemical Engineering, 2 (2014) 2229-2235. 
[16] T.T. Vu, L. del Río, T. Valdés-Solís, G. Marbán, Fabrication of wire meshsupported $\mathrm{ZnO}$ photocatalysts protected against photocorrosion, Applied Catalysis B: Environmental, 140-141 (2013) 189-198.

[17] T.T. Vu, L. del Río, T. Valdés-Solís, G. Marbán, Stainless steel wire meshsupported $\mathrm{ZnO}$ for the catalytic photodegradation of methylene blue under ultraviolet irradiation, Journal of Hazardous Materials, 246-247 (2013) 126-134.

[18] T.T. Vu, L. Del Río, T. Valdés-Solís, G. Marbán, Tailoring the synthesis of stainless steel wire mesh-supported ZnO, Materials Research Bulletin, 47 (2012) 1577 1586.

[19] A. Fernández-Pérez, V. Rodríguez-Casado, T. Valdés-Solís, G. Marbán, Room temperature sintering of polar $\mathrm{ZnO}$ nanosheets: I-evidence, Physical Chemistry Chemical Physics, 19 (2017) 16406-16412.

[20] A. Fernández-Pérez, V. Rodríguez-Casado, T. Valdés-Solís, G. Marbán, Room temperature sintering of polar $\mathrm{ZnO}$ nanosheets: II-mechanism, Physical Chemistry Chemical Physics, 19 (2017) 16413-16425.

[21] A. Di Mauro, M.E. Fragalà, V. Privitera, G. Impellizzeri, ZnO for application in photocatalysis: From thin films to nanostructures, Materials Science in Semiconductor Processing, 69 (2017) 44-51.

[22] A. Mills, An overview of the methylene blue ISO test for assessing the activities of photocatalytic films, Applied Catalysis B: Environmental, 128 (2012) 144-149.

[23] T.T. Vu, G. Marbán, Sacrificial template synthesis of high surface area metal oxides. Example: An excellent structured Fenton-like catalyst, Applied Catalysis B: Environmental, 152-153 (2014) 51-58.

[24] M. Kruk, M. Jaroniec, A. Sayari, Application of large pore MCM-41 molecular sieves to improve pore size analysis using nitrogen adsorption measurements, Langmuir, 13 (1997) 6267-6273.

[25] H. Benhebal, M. Chaib, T. Salmon, J. Geens, A. Leonard, S.D. Lambert, M. Crine, B. Heinrichs, Photocatalytic degradation of phenol and benzoic acid using zinc oxide powders prepared by the sol-gel process, Alexandria Engineering Journal, 52 (2013) 517-523.

[26] A. Mang, K. Reimann, S. Rübenacke, Band gaps, crystal-field splitting, spin-orbit coupling, and exciton binding energies in $\mathrm{ZnO}$ under hydrostatic pressure, Solid State Communications, 94 (1995) 251-254.

[27] Z.N. Kayani, F. Saleemi, I. Batool, Effect of calcination temperature on the properties of ZnO nanoparticles, Applied Physics A, 119 (2015) 713-720.

[28] E. Mornani, P. Mosayebian, D. Dorranian, K. Behzad, Effect of calcination temperature on the size and optical properties of synthesized $\mathrm{ZnO}$ nanoparticles, Journal of Ovonic Research Vol, 12 (2016) 75-80. 
[29] N.M. Al-Hada, E. Saion, A. Shaari, M. Kamarudin, S.A. Gene, The influence of calcination temperature on the formation of zinc oxide nanoparticles by thermaltreatment, in: Applied Mechanics and Materials, Trans Tech Publ, 2014, pp. 181-184.

[30] S.R. Kanel, S.R. Al-Abed, Influence of $\mathrm{pH}$ on the transport of nanoscale zinc oxide in saturated porous media, Journal of Nanoparticle Research, 13 (2011) 4035-4047.

[31] D. Collins, T. Luxton, N. Kumar, S. Shah, V.K. Walker, V. Shah, Assessing the impact of copper and zinc oxide nanoparticles on soil: a field study, PLoS One, 7 (2012) e42663.

[32] E.H. Jones, C. Su, Transport and retention of zinc oxide nanoparticles in porous media: Effects of natural organic matter versus natural organic ligands at circumneutral pH, Journal of Hazardous Materials, 275 (2014) 79-88.

[33] Y. Wang, R. Shi, J. Lin, Y. Zhu, Significant photocatalytic enhancement in methylene blue degradation of $\mathrm{TiO}_{2}$ photocatalysts via graphene-like carbon in situ hybridization, Applied Catalysis B: Environmental, 100 (2010) 179-183.

[34] P. Manoj Kumar Reddy, B. Rama Raju, J. Karuppiah, E. Linga Reddy, C. Subrahmanyam, Degradation and mineralization of methylene blue by dielectric barrier discharge non-thermal plasma reactor, Chemical Engineering Journal, 217 (2013) 4147.

[35] H. Fu, T. Xu, S. Zhu, Y. Zhu, Photocorrosion Inhibition and Enhancement of Photocatalytic Activity for $\mathrm{ZnO}$ via Hybridization with $\mathrm{C} 60$ Environmental Science and Technology, 42 (2008) 8064-8069.

[36] A.L. Rudd, Photo-induced dissolution of zinc in alkaline solutions, Electrochimica Acta, 45 (2000) 1571-1579.

[37] B. Neppolian, H.C. Choi, S. Sakthivel, B. Arabindoo, V. Murugesan, Solar/UVinduced photocatalytic degradation of three commercial textile dyes, Journal of Hazardous Materials, 89 (2002) 303-317.

[38] J.M. Donohue, C.O. Abernathy, P. Lassovszky, G. Hallberg, Rolling Revision of the WHO Guidelines for Drinking-Water Quality, World Health, (2004).

[39] Z. Meng, X. Zhang, J. Qin, A high efficiency microfluidic-based photocatalytic microreactor using electrospun nanofibrous $\mathrm{TiO}_{2}$ as a photocatalyst, Nanoscale, 5 (2013) 4687-4690.

[40] N. Padoin, L. Andrade, J. Ângelo, A. Mendes, R.d.F.P.M. Moreira, C. Soares, Intensification of photocatalytic pollutant abatement in microchannel reactor using $\mathrm{TiO}_{2}$ and $\mathrm{TiO}_{2}$-graphene, AIChE Journal, 62 (2016) 2794-2802.

[41] X. Wang, Z. Liu, N.Y. Chan, H.W. Chan, X. Zhang, Photocatalytic microfluidic reactor with a novel compound catalyst film using solar energy, in: Proceedings of the 16th International Conference on Miniaturized Systems for Chemistry and Life Sciences, MicroTAS 2012, 2012, pp. 1993-1995. 
[42] T.T. Vu, T. Valdés-Solís, G. Marbán, Novel high surface area stainless steel wire mesh supported $\mathrm{Ni}_{0.7} \mathrm{Zn}_{0.3} \mathrm{O}$ solid solution prepared by room temperature sacrificial template accelerated hydrolysis. Application in the production of hydrogen from methanol, Applied Catalysis B: Environmental, 160-161 (2014) 57-66. 


\section{Captions to figures}

Figure 1. Flow-through reactor. A) Photograph of the reaction system, B) Schematic representation.

Figure 2. Properties of SSWM-supported photocatalysts $\left(\mathrm{T}_{\mathrm{C}}=210^{\circ} \mathrm{C}, \mathrm{ZnO}\right.$ yield $=\sim 20$ wt.\%) prepared by the unmodified or modified synthesis methods. A) Photograph; B and C) SEM images; D) XRD patterns of the $\mathrm{ZnO}$ catalysts and a commercial $\mathrm{ZnO}$ powder; E) $\mathrm{N}_{2}$ physisorption isotherms (inset: pore size distributions).

Figure 3. Adhesion test results for SSWM-supported $\mathrm{ZnO}$ samples prepared in the presence or absence of Triton ${ }^{\mathrm{TM}} \mathrm{X}-100$ and/or Methylene blue.

Figure 4. Evolution of methylene blue conversion with time for the SSWM-supported catalysts with different $\mathrm{ZnO}$ yields.

Figure 5. Evaluation of $\mathrm{pH}_{\mathrm{pzc}}$ for $\mathrm{SSWM}$-supported $\mathrm{ZnO}\left(\mathrm{T}_{\mathrm{C}}=210^{\circ} \mathrm{C}, \mathrm{ZnO}\right.$ yield $=$ $\sim 20 \mathrm{wt} . \%)$ and a commercial $\mathrm{ZnO}$ powder.

Figure 6. Evolution of methylene blue conversion with time for the SSWM-supported catalysts prepared at different calcination temperatures.

Figure 7. Consecutive reaction cycles intercalated by regeneration steps for SSWMsupported $\mathrm{ZnO}\left(\mathrm{T}_{\mathrm{C}}=250^{\circ} \mathrm{C}, \mathrm{ZnO}\right.$ yield $\left.=\sim 23 \mathrm{wt} . \%\right)$. 


\section{Tables}

Table 1. Structural, textural and optical parameters of the SSWM-supported ZnO materials

\begin{tabular}{ccccc}
\hline $\begin{array}{c}\text { ZnO yield } \\
(\mathbf{w t} \%)\end{array}$ & $\begin{array}{c}\mathbf{T}_{\mathbf{C}}=\text { calcination } \\
\text { temperature }\left({ }^{\circ} \mathbf{C}\right)\end{array}$ & $\begin{array}{c}\text { Crystal } \\
\text { size }(\mathbf{n m})\end{array}$ & $\begin{array}{c}\text { BET specific } \\
\text { surface } \mathbf{a r e a}\left(\mathbf{m}^{2} / \mathbf{g}\right)\end{array}$ & $\begin{array}{c}\text { Band-gap } \\
(\mathbf{e V})\end{array}$ \\
\hline 8.0 & 210 & 8.0 & 103 & 3.33 \\
15.7 & 210 & 9.1 & 111 & 3.36 \\
18.5 & 210 & 9.4 & 115 & 3.34 \\
31.0 & 210 & 7.5 & 124 & 3.28 \\
33.5 & 210 & 8.3 & 103 & 3.33 \\
25.9 & 250 & 8.7 & 92.8 & 3.22 \\
19.3 & 350 & 14.2 & 26.5 & 3.18 \\
16.5 & 450 & 22.3 & 24.3 & 3.18 \\
\hline
\end{tabular}

Table 2. Results of MB photodegradation in the flow-through reactor

\begin{tabular}{|c|c|c|c|c|c|c|}
\hline $\begin{array}{c}\mathbf{T}_{\mathbf{C}} \\
\left({ }^{\circ} \mathbf{C}\right)\end{array}$ & $\begin{array}{c}\text { ZnO yield } \\
(\text { wt. } \%)\end{array}$ & $\begin{array}{l}\mathbf{W}_{\mathrm{ZnO}} \\
(\mathrm{mg})\end{array}$ & $\begin{array}{c}\mathrm{X}_{\mathrm{MB}} \text { at } \mathrm{t}=\mathbf{3} \mathrm{h} \\
(\%)\end{array}$ & $\begin{array}{c}\mathrm{X}_{\mathrm{MB}} \text { at } \mathrm{t}=17 \mathrm{~h} \\
(\%)\end{array}$ & $\begin{array}{c}\mathrm{X}_{\text {TOC }} \text { at } \mathrm{t}=17 \mathrm{~h} \\
(\%)\end{array}$ & $\begin{array}{l}\mathrm{LZnO}^{*} \\
\text { (wt.\%) }\end{array}$ \\
\hline 210 & 5.1 & 11.4 & 68.9 & 54.9 & 21.6 & 13.7 \\
\hline 210 & 8.4 & 19.6 & 65.2 & 60.6 & 22.2 & 8.7 \\
\hline 210 & 16.6 & 42.3 & 63.6 & 56.7 & 21.0 & 4.5 \\
\hline 210 & 19.9 & 55.4 & 66.5 & 58.1 & 26.6 & 3.6 \\
\hline 210 & 28.5 & 80.3 & 60.5 & 59.1 & 26.0 & 2.1 \\
\hline 210 & 33.4 & 113.7 & 59.2 & 51.4 & 31.4 & 1.0 \\
\hline 210 & 42.9 & 153.2 & 68.5 & 64.5 & - & 1.5 \\
\hline 250 & 22.7 & 62.0 & 54.6 & 43.0 & 19.4 & 1.7 \\
\hline 350 & 21.6 & 58.4 & 64.4 & 47.7 & - & 1.7 \\
\hline 450 & 19.4 & 51.5 & 71.8 & 52.2 & 27.2 & 1.2 \\
\hline
\end{tabular}

$* \mathrm{ZnO}$ loss at the end of reaction due to photocorrosion 
Table 3. Comparison of micro-reactor systems for MB photodegradation

\begin{tabular}{|c|c|c|c|c|}
\hline Reference & This work & Meng et al.[39] & $\begin{array}{c}\text { Padoin et } \\
\text { al. }[40]\end{array}$ & Wang et al.[41] \\
\hline Reactor & Flow-through & $\begin{array}{l}\text { Micro-fluidic- } \\
\text { based }\end{array}$ & $\begin{array}{l}\text { Micro-fluidic- } \\
\text { based }\end{array}$ & $\begin{array}{l}\text { Micro-fluidic- } \\
\text { based }\end{array}$ \\
\hline Catalyst & $\begin{array}{c}\text { SSWM- } \\
\text { supported ZnO }\end{array}$ & $\begin{array}{c}\text { Nanofibrous } \\
\mathrm{TiO}_{2}\end{array}$ & $\mathrm{TiO}_{2} \mathrm{P} 25$ & $\begin{array}{l}\mathrm{BiVO}_{4} \text { thin } \\
\text { porous film }\end{array}$ \\
\hline Lamp & $\begin{array}{c}\text { Dr Gröbel UV } \\
\text { LQ400 }\end{array}$ & $\begin{array}{c}\text { UV-LED } 365 \\
\mathrm{~nm}\end{array}$ & UV-A-365 nm & $\begin{array}{l}\text { Low-cost blue- } \\
\text { light panel LED }\end{array}$ \\
\hline $\begin{array}{l}\text { Irradiance } \\
\left(\mathbf{m W} / \mathbf{c m}^{2}\right)\end{array}$ & 9.9 & 50 & 0.6 & 140 \\
\hline $\begin{array}{l}\text { Reactor volume } \\
\left(\mathbf{m}^{\mathbf{3}}\right)\end{array}$ & $9.9 \times 10^{-8} *$ & $1.2 \times 10^{-6}$ & $1.3 \times 10^{-8}$ & $1.0 \times 10^{-8}$ \\
\hline Reactant & Methylene blue & Methylene blue & Methylene blue & Methylene blue \\
\hline $\mathrm{C}_{0}(\mathrm{ppm})$ & 10 & 10 & 10 & 9.6 \\
\hline Flow $\left(\mathrm{cm}^{3} / \mathrm{h}\right)$ & 20 & 6 & 5.4 & 2.3 \\
\hline $\begin{array}{l}\text { Residence Time } \\
\text { (s) }\end{array}$ & 17.8 & 12.4 & 8.6 & 16.0 \\
\hline $\begin{array}{l}\text { Maximum } \\
\text { conversion (\%) }\end{array}$ & $64.6 * *$ & 56.9 & 18.3 & 39.0 \\
\hline $\begin{array}{l}\text { Activity } \\
{\left[\mathbf{m g} /\left(\mathbf{m}^{3} h\right)\right]}\end{array}$ & $1.3 \times 10^{6}$ & $2.8 \times 10^{4}$ & $7.7 \times 10^{5}$ & $8.4 \times 10^{5}$ \\
\hline
\end{tabular}

*Volume of the irradiated photocatalytic disc; **Averaged for all catalysts in Figure 4 at $\mathrm{t}=10^{4} \mathrm{~s}$ 


\section{Figures}
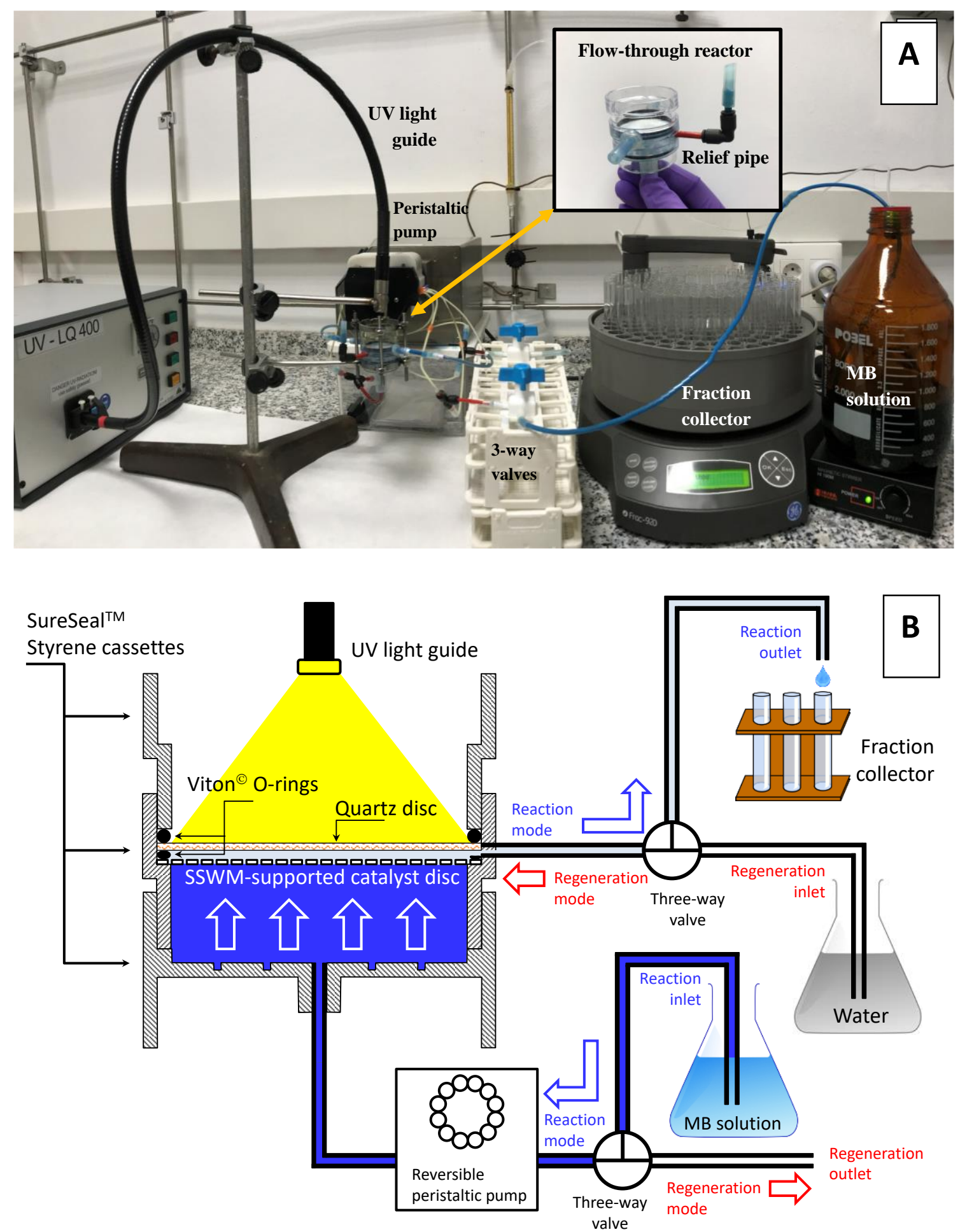

Figure 1 

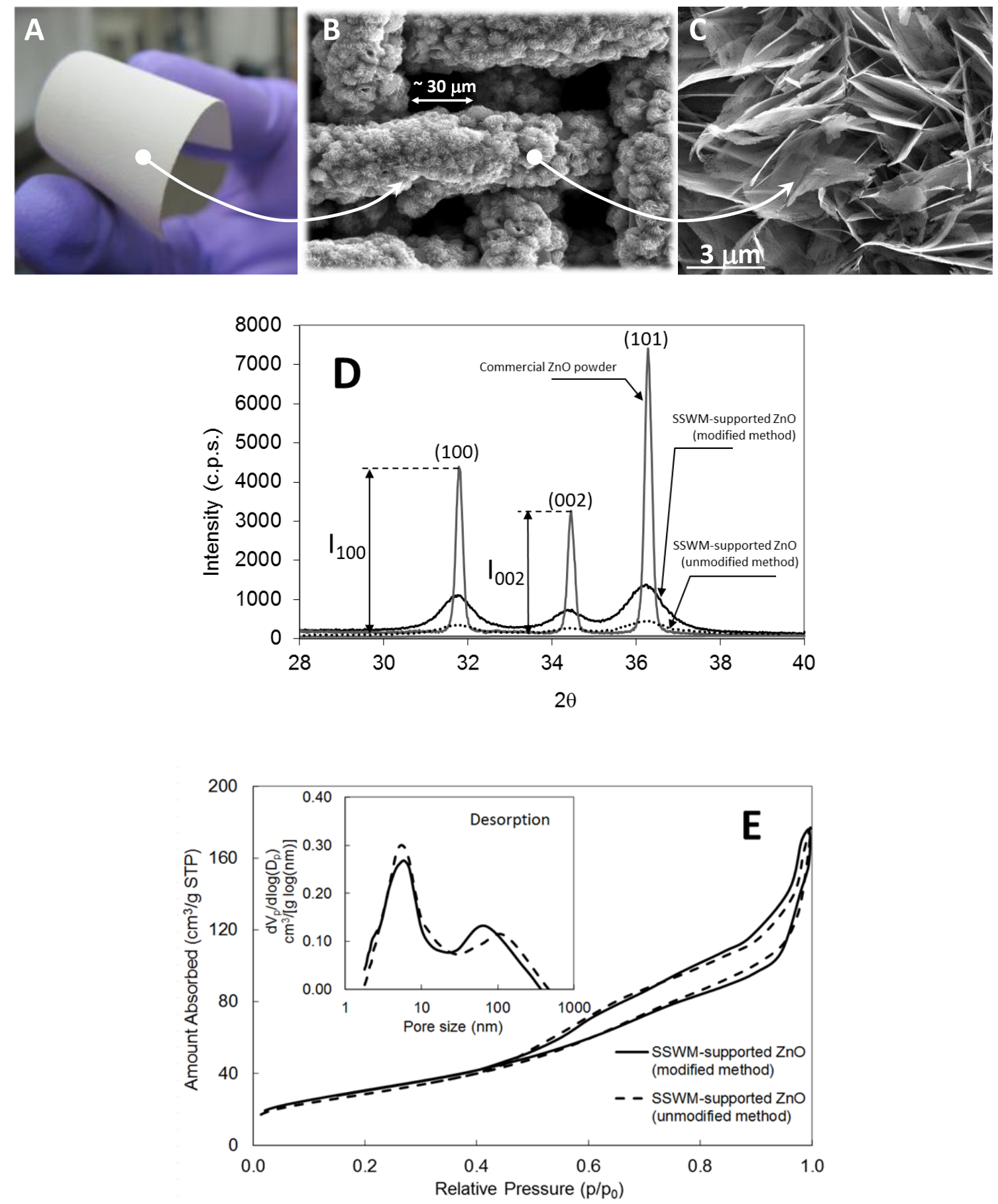

Figure 2 


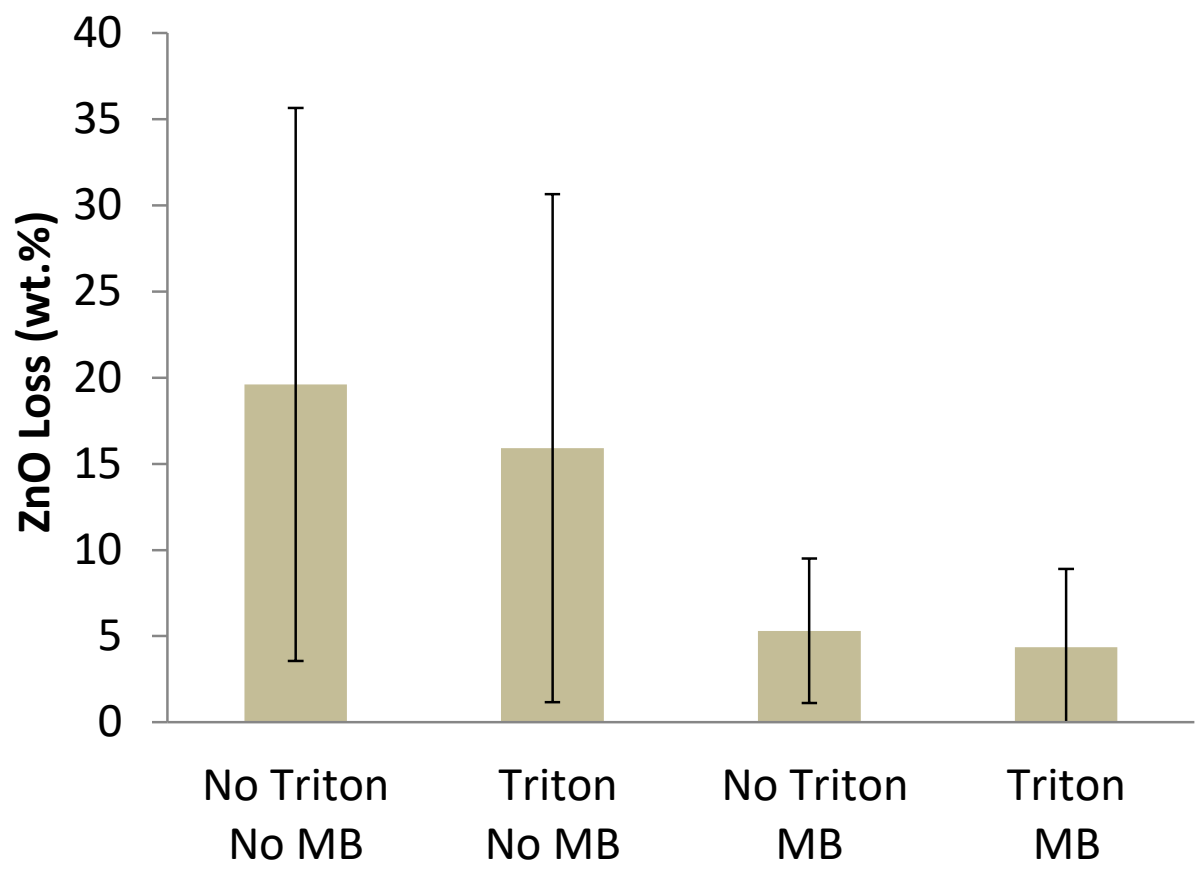

Figure 3 


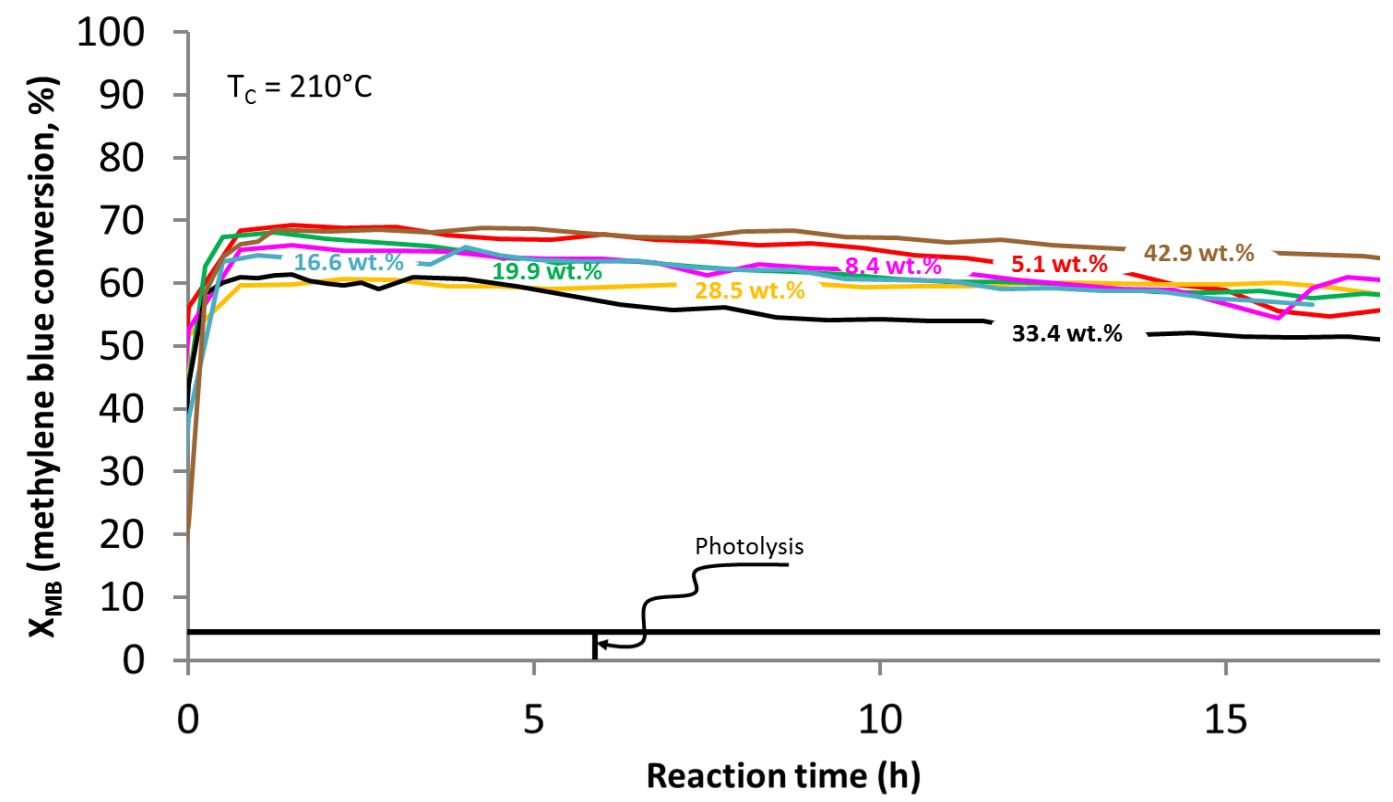

Figure 4 


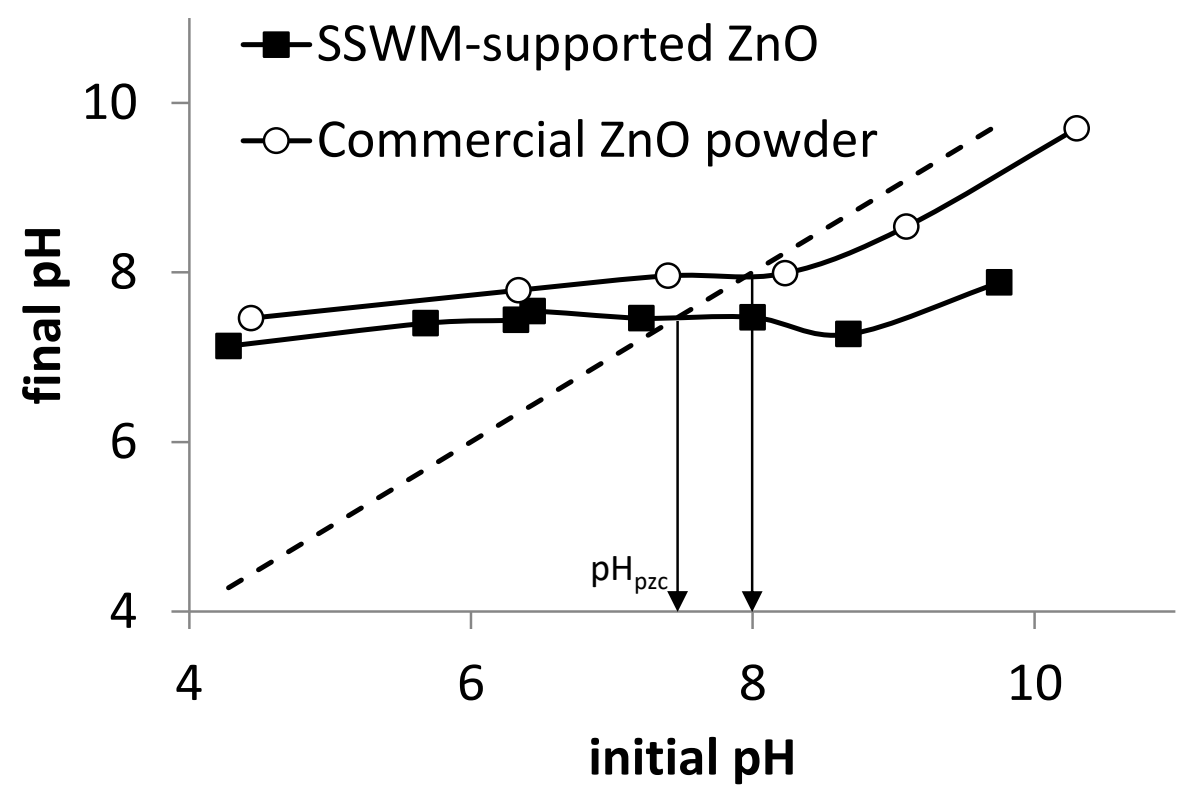

Figure 5 


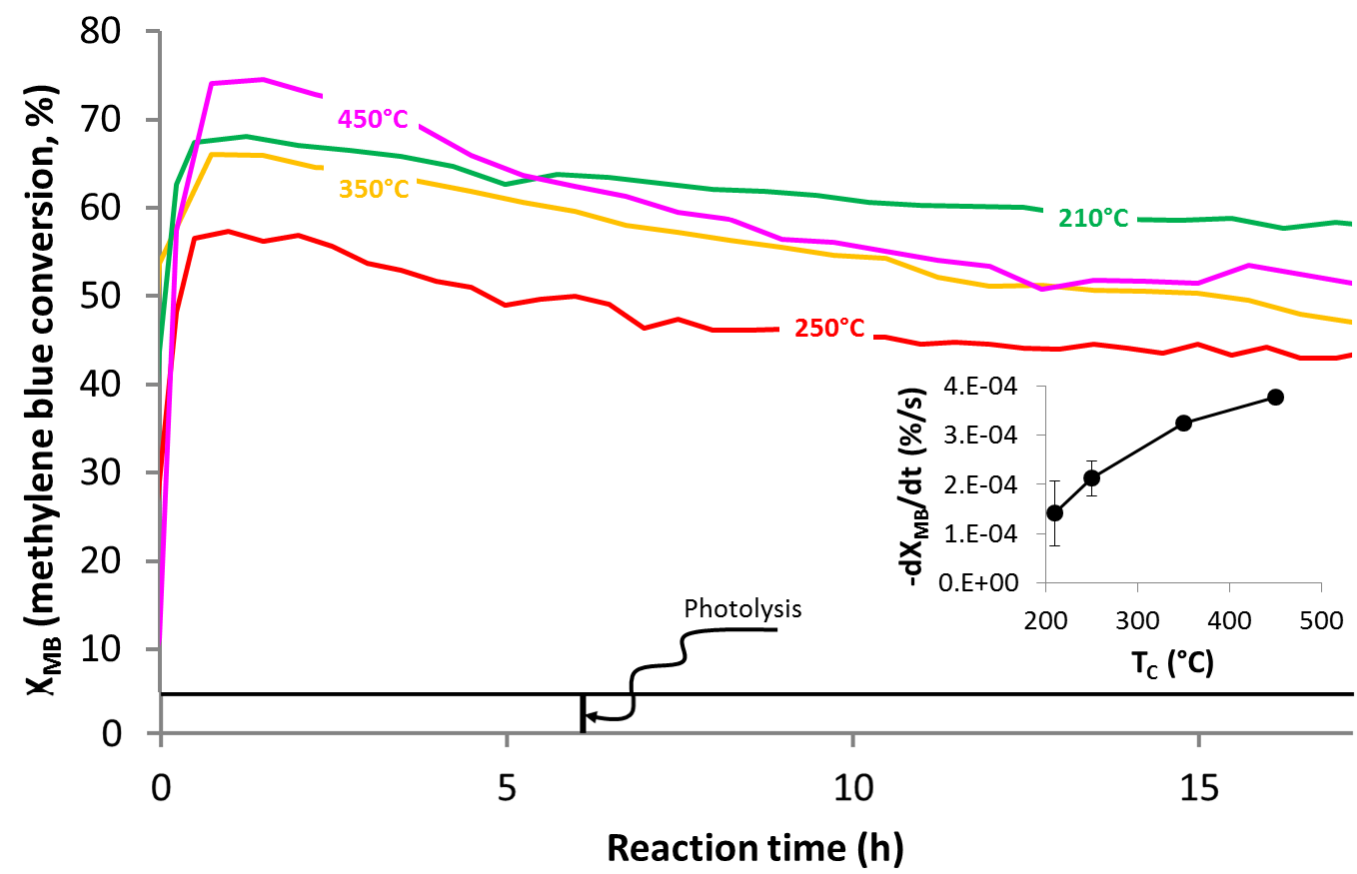

Figure 6 


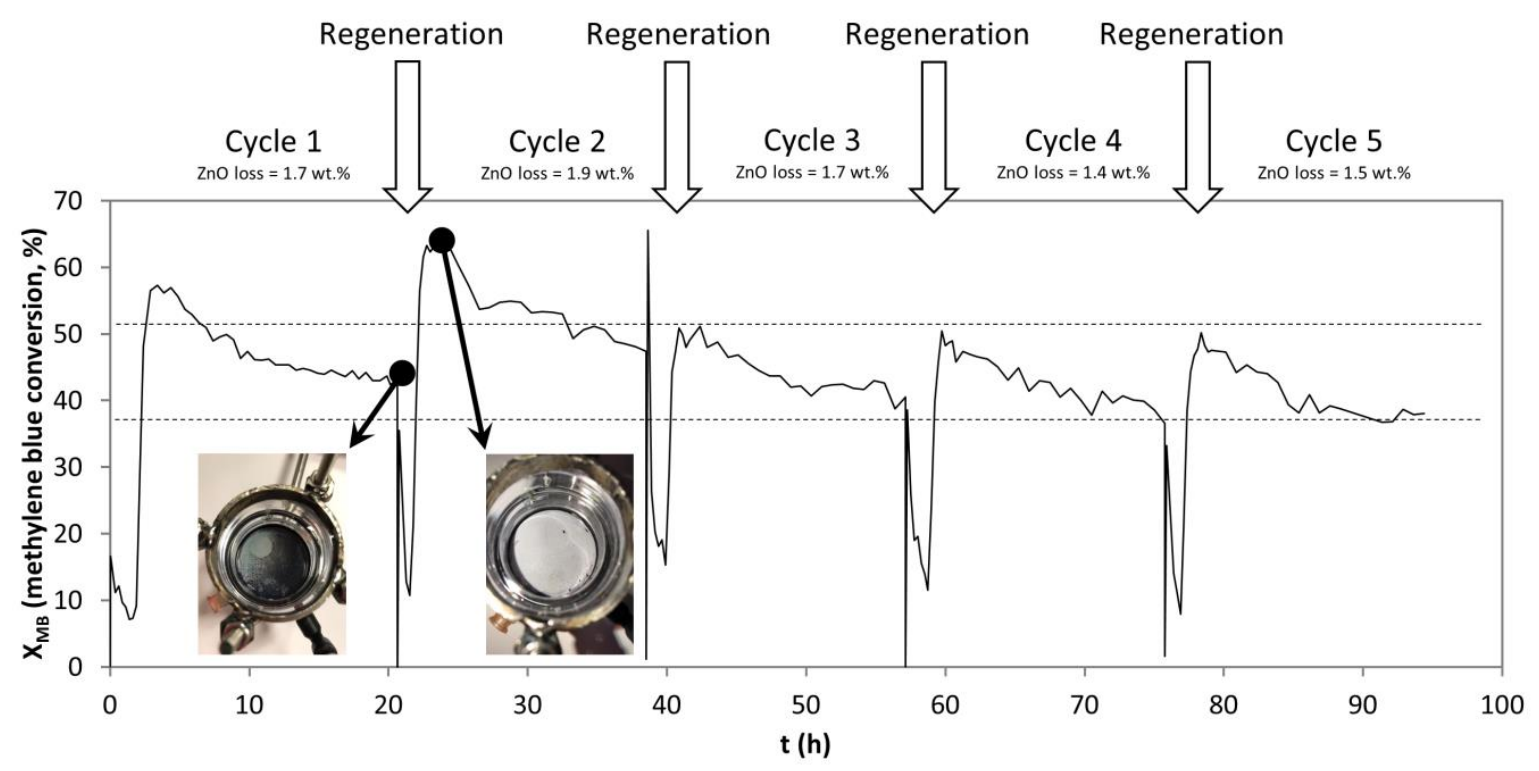

Figure 7 